\title{
Vertical separation vs. independent downstream entry in an electricity network: experimental insights
}

Article

Accepted Version

Creative Commons: Attribution-Noncommercial-No Derivative Works 4.0

Ciarreta, A., Fatas, E., Georgantzis, N. and Gutiérrez-Hita, C. (2017) Vertical separation vs. independent downstream entry in an electricity network: experimental insights. Electric Power Systems Research, 143. pp. 728-738. ISSN 0378-7796 doi: https://doi.org/10.1016/j.epsr.2016.10.034 Available at https://centaur.reading.ac.uk/67972/

It is advisable to refer to the publisher's version if you intend to cite from the work. See Guidance on citing.

Published version at: http://dx.doi.org/10.1016/j.epsr.2016.10.034

To link to this article DOI: http://dx.doi.org/10.1016/j.epsr.2016.10.034

Publisher: Elsevier

All outputs in CentAUR are protected by Intellectual Property Rights law, including copyright law. Copyright and IPR is retained by the creators or other copyright holders. Terms and conditions for use of this material are defined in the End User Agreement.

www.reading.ac.uk/centaur 
Central Archive at the University of Reading

Reading's research outputs online 


\title{
Vertical separation vs. independent downstream entry in an electricity network: Experimental insights"
}

\author{
Aitor Ciarreta \\ Dpt. of Economic Analysis, University of the Basque Country, BETS and BRiDGE \\ Enrique Fatas \\ University of East Anglia \\ Nikolaos Georgantzís \\ University of Reading \\ Carlos Gutiérrez-Hita \\ Dpt. of Economic and Financial Studies and GATHER, University Miguel Hernández
}

\begin{abstract}
We analyze a realistic simulation of a complex electricity network. We obtain the data with a series of experimental sessions designed to closely replicate the Spanish Electricity Market. In the experiments reported here we compare the status quo with two alternative regulatory market structures. In one of them, labeled as vertical separation, we impose that power generating firms and electricity distributors operate as independent business groups. In the second, we study the effect of entry by independent end-suppliers. Both alternative scenarios dominate the status quo in terms of market efficiency, but the latter of them dominates the former.
\end{abstract}

Keywords: Spanish Electricity Market, Vertical Relations, Laboratory Experiments

\footnotetext{
\# Authors thank the NET Institute (www.NETinst.org) for financial support. Aitor Ciarreta would like to acknowledge financial support from Ministerio de Economía y Competitividad (ECO2012-35820) and Gobierno Vasco (IT383-12). Carlos GutiérrezHita would like to acknowledge financial support from Ministerio de Ciencia e Innovación (MTM2011-23205).
} 


\section{Introduction}

Regulatory regimes in energy markets are to a large extent the consequence of a country's technological development and political history. The performance of different regimes is hard to assess ex-ante, given that the same objective (economic efficiency) has been invoked to implement a plethora of different solutions. Given the complexity of energy systems and the difficulty of getting solid counterfactuals, policy alternatives cannot be easily compared on a purely empirical basis. As the numbers of natural experiments is limited, the empirical analysis of regime changes in energy markets typically follows an ex-post basis. ${ }^{1}$ Real-world data include little if any information on alternative scenarios. Moreover, firms are averse to changes in regulation that affect the type and number of potential competitors. ${ }^{2}$

The natural alternative is theoretical analysis. Models based on abstract settings, reduced complexity and, in the best of the cases, simple dynamics sacrifice realism to gain analytical tractability. Theoretical predictions are most of the times neither immediately testable nor applicable. In this paper we explore an alternative method: laboratory experiments. Relative to other empirical methods using energy market data, experiments enjoys a superior control over the data generating process. While data on alternative regulatory regimes is difficult to obtain in the field, experiments may challenge almost any status quo with several alternative counterfactuals. The external validity of the experimental results is stressed by focusing on comparative statics (how behavior changes when the regulation changes) rather than on individual behavior itself. Relative to its cousins, the theoretical models, we believe experiments may help the dialogue between policymakers, academics and practitioners with a limited but non-negligible number of intuitions about the viability of different solutions. Not surprisingly, different experiments have recently analyzed electricity markets. Ferreira et al. (2009) and Brandts et al. (2008) test the strategic scope of selling forward in the framework of Cournot, Supply Function competition and Multi-unit auctions settings. Ede et al. (2001) focus on market power abuse by generators. Our study contributes to this literature by analyzing a realistic experimental setting in which we study two alternative structural changes in the Spanish Electricity Market (SEM), hereafter.

EU requirements to create and improve an effective electricity market in each member state moved governments to design more competitive regulations in European electricity sectors (Directive 96/92/EC). Spain is an informative example of this tendency. In Spain until 1996 there was no effective market to trade electricity and five companies possessed all the generation power, controlled transmission networks, and local distribution grids. In 1997 the organization of the electricity market was transformed by Law 54/1997. This law liberalized the market for electricity generation and introduced a spot market for electricity which started operations in January $1998 .^{3}$ OMEL (the electricity market operator, now OMIE) is the entity that manages the bidding system

\footnotetext{
${ }^{1}$ Learning valid lessons from wrong policy remedies have resulted to be expensive, as the California experience and the fall of the English and Welsh electricity markets suggest.

2 For instance, see Nillesen and Pollit (2011) for New Zealand. They find that ownership unbundling did not increase competition in the supply side although there were efficiency gains in terms of lower cost and higher quality of service. See also Mansur (2007) for PJM. He finds that restructuring of PJM led to anticompetitive behaviour by large net sellers, although vertical integration mitigates its impact.

3 This followed liberalization in the UK electricity market and was implemented simultaneously with liberalization in California.
} 
and the subsequent monetary transfers between agents. In 2007 both the Portuguese and Spanish electricity market merged operations and the Iberian market operator MIBEL was created. Since then, OMIE manages the Spanish Electricity Pole. ${ }^{4}$

Despite this liberalization process, there is still a high concentration in both the generation and distribution sectors. Besides, larger generators act also as buyers in the pool. As a result, Spain's large electricity companies are active on both sides of the wholesale electricity spot market, selling electricity as generators and buying it from the spot market as retailers. This feature together with an inelastic demand suggests that being market power still concentrated in a few firms, pricesetting behavior can be largely non competitive (see for instance Loertsche and Reisinger, 2011). ${ }^{5}$ This is the starting hypothesis in this paper. The status quo in the SEM is a vertically integrated structure in which firms exert an effective and significant market power. Furthermore, we argue that new entrants in the retail sector or the elimination of vertically integrated firms could imply a further enhancement of market efficiency.

We test these two possibilities using data obtained from a quite realistic and complex laboratory experiment based on the Power Market simulator ${ }^{6}$ (hereinafter, $P M \circledR$ ) initially designed to replicate in the lab the demand and supply characteristics of the SEM over a combination of seasonal data on hydraulicity and weather conditions. The status quo is then modified to address two alternative market structures aimed at improving the functioning of the market. First, we consider a market in which generators and distributors are independent firms. Second, we contemplate the entry of independent distributors.

A general perception is that vertical integration allows firms to mitigate transaction cost as well as some sort of asymmetric information problem arising from upstream-downstream contractual relations (see for instance Williamson (1971) for a classical analysis). Moreover, market liberalization has to consider two opposite effects of unbundling: (i) the (possible) efficiency losses in terms of cost of pure generation and distribution activities; (ii) the (expected) lower prices due to liberalization. Based on these arguments the issue of unbundling generation and distribution activities should take into account both pro-competitive effects and anti-competitive ones.

The complexity of the experimental protocol described in section 3 below was our first challenge. In that sense, it is maybe not surprising that we were interested in learning about the internal validity of the method chosen. Even when our participants were more qualified than the standard participants used in regular experiments, the amount of information they had to process to make an unusually large number of round decisions was demanding. Our results strongly suggest that the laboratory data obtained are sensitive to the underlying experimental conditions. Prices and quantities follow quite reasonably the seasonal and daily demand fluctuations. Moreover, the

\footnotetext{
${ }^{4}$ Before the Iberian electricity market was created in July 2007, two firms, Endesa (EN) and Iberdrola (IB) owned more than 70 percent of the total generation capacity. After that, Electricidade de Portugal (EDP) is the third largest firm in the market. However, vertical integration remains in the integrated market.

5 They find pro-competitive effects of vertical integration the larger the more concentrated the market is. Although the context is oligopolistic at upstream and downstream markets, that market structure is not the current situation in most of the electricity markets in Europe. Regulation in distribution raises incentives to increase prices.

${ }^{6}$ Power Market ${ }^{\circledR}$. Examples of screen shots for decision submission and feedback are provided in Appendix 1. See also the experimental design in Section 3.
} 
comparative statics between the alternative regulatory scenarios is quite robust to the level of analysis chosen. This is a positive finding regarding the validity of this instrument for policy recommendations in the real world.

Our analysis of the counterfactual scenarios yields a not surprising but interesting result: both alternative structures lead to lower prices in the SEM. This result is interesting because it collides with current organization of many electricity networks. Thus, we provide evidence that supports unbundling of generation and distribution activities in markets with regulated distribution. Two features of our replication based in $P M{ }^{\circledR}$ have been neglected in previous work. First, the sector ability to deal with demand and supply specific uncertainty has never been analyzed in deep (e.g. including daily and seasonal variations). Second, the frequency with which unfavorable demand or supply conditions, or strategic behavior, leads to the interruption of electric energy provision. In that respect, our analysis helps to understand the behavioral reaction of firms to regulatory changes currently implemented in an increasing number of countries aiming at a more competitive price formation mechanism. The complexity of the experiment seeks to highlight some of the larger likelihood of market power abuse in vertically integrated markets.

The paper is structured as follows. Section two reviews the literature on electricity markets focusing on the issue of market structure. Section three describes the experimental design whereas Section four and five present the main results and conclusions, respectively. An appendix offers additional information on the $P M{ }^{\circledR}$ software.

\section{Literature review}

Following the prerequisites proposed by Haas and Auer (2006), the restructuring of the electricity sector should be based on two general types of measures: those affecting the market functioning and those aimed at changes in the market structure and, specifically, the separation between generation and distribution activities.

Most of the research on the first measure deals with specific rules mitigating market power in wholesale electricity markets organized as pools. Among that type of literature, a number of papers used experimental frameworks to highlight pros and cons of those that affects market functioning. Kiesling and Wilson (2007) examine a class of Automatic Mitigation Procedures (AMPs) on prices and capacity investment choices in the presence of market power. Whereas longrun prices are driven by investment in new capacity, the class of AMPs studied does not affect investment on capacity. Shawhan et al. (2011) run an experiment in order to test the effects of AMPs in suppressing the exercise of market power. They replicate the market conditions of the New York Independent System Operator and find that AMP keeps market prices close to marginal cost only when generators of electricity have low market power in uncongested periods.

Several authors have studied the performance of firms involved in the generation and distribution of electricity in Spain. There is a wide consensus on the risks of the market clearing mechanism used, as it may facilitate collusion. Fabra and co-authors (Fabra, 2003; Fabra et al. 2006a; Fabra and Toro, 2006b) argue that the auction used to clear the market increases the ability 
of firms to sustain over-competitive prices. Ciarreta and Gutiérrez-Hita (2006), Ciarreta and Espinosa (2009), and Marin and Garcia-Diaz (2003) reach similar conclusions.

In this paper we focus in the second type of measures mentioned above; namely, changes in the market structure. Green (1996) pioneered the study of competition in electricity spot markets. His analysis of the British market delivers a clear recommendation: partial divestiture may decrease the deadweight loss. Moreover, encouraging competitive entry may reduce welfare. ${ }^{7}$ Some empirical studies ${ }^{8}$ have already addressed the effects of vertical integration on market efficiency. The basic idea is to assess the trade-off between the saving costs obtained by vertical integration and the competitive effects of unbundling. Not surprisingly, the net effect critically depends on the number of upstream and downstream competitors. An extensive revision of this empirical literature can be found in Sionshiasi (2008). The collection of case studies included in this paper suggests that market reforms may lead to undesirable consequences for end-consumers when the market power retained by firms is high.

While the analysis of market entry has received less attention, the joint effect of vertical disintegration and entry has never been studied in a systematic way in the laboratory. Rassenti et al. (2003) find that demand-side bidding completely neutralizes the exercise of market power. ${ }^{9}$ In this paper, we focus on two structural market changes. The first one breaks the vertical links between generators and distributors of electricity; the second allows the entry of independent firms in the distribution of electricity. Given the dynamic and complex nature of the market, none of these two types of changes is expected to cause trivially predictable results.

Rather than simplifying the features of the industry, we choose to replicate them in the lab. Our experimental markets are affected by demand and supply dynamics, weather uncertainty, and technological asymmetries associated with firms' generation plant configurations. Only a few studies have independently considered some of these issues. Arocena et al. (1999) present a survey focused on the SEM. Agosti et al (2007) measure its static and dynamic efficiency and Ciarreta and Espinosa (2010) find evidence of how market conditions affect the exercise of market power by larger generators. Without underestimating these alternative approaches, largely based on abstract setups of reduced complexity, we see the experiment reported here as a complementary, but necessary step towards a better understanding of the effect of daily and seasonal fluctuations on demand, supply and market outcomes.

In this paper we emphasize the role that complexity, uncertainty and dynamic considerations play in the functioning of markets. Our experiment takes us as close as one can

\footnotetext{
${ }^{7}$ A general modeling approach can be found in Newbery (1999) and Stoft (2000). These articles focus on market design and the effects that privatization and regulation rules have on such markets.

${ }^{8}$ See for example, Kwoka (2002) who looks at alternative vertical structures in the US electric market.

${ }^{9}$ Rassenti and Smith (2008) is an insightful revision of experimental designs on the functioning of wholesale electricity markets. Staropoli and Jullien (2006) also revise the contribution of laboratory experiments up to this date to understand the functioning of wholesale electricity markets. They focus in the market architecture but also ancillary rules to argue that complementary approaches to auction theory are very useful to regulator authorities to improve market efficiency. In particular, experimental economics reveals as a useful framework to simulate alternative scenarios.
} 
realistically imagine to the real world case. In addition to the control gained in the laboratory, we see the realism of $P M \circledR$ software as an important value added of our approach.

\section{Methodology and Experimental Design}

The Experimental Economics Laboratories of Valencia (LINEEX, http://www.uv.es/lineex) and Castellón (LEE, http://www.lee.uji.es) possess a unique experimental environment which was constructed, following electric engineers' advice, to simulate the exact supply and demand conditions (including weather variations and both daily and seasonal demand fluctuations) experienced by generators and distributors in the Spanish wholesale electric market. Accordingly, experimental subjects' interface has been developed in a way which reflects the electricity technology mix specifications as well as those capacities and restrictions faced by generator firms. The result of this effort has been materialized in the aforementioned experimental software $P M{ }^{\circledR}$ which is joint intellectual property of the two laboratories. The market-clearing mechanism implemented resembles all the details of the bidding system adopted in the Spanish wholesale electricity market. The market operator OMIEL (Iberian electricity market operator) constructs with the selling and the purchasing bids an aggregate supply and an aggregate demand schedule, respectively. In a session of the daily market, it combines these offers matching demand and supply for each of the 24 hours and determines the equilibrium price for each period, the System Marginal Price (SMP), and the amount traded, the Market Clearing Quantity (MCQ). The SMP at each hour is determined under a uniform-price auction where the price sale offer is made by the last generation unit whose entry into the system was required to meet demand for electricity. Daily demand fluctuations produce prices which follow the usual pattern: "Extreme Peak" prices are higher than "Peak" prices, the latter are higher than "Semi-valley" prices which are higher than "Valley" prices.

As it is usual, a first set of sessions was run to make the experimental subjects familiar with market rules as well as to ensure that they behave in an economically meaningful way which reproduces the current situation of the market.

As mentioned above, the experiment whose results are analyzed here is based on a threetreatment design aimed at studying two alternative scenarios concerning the future of the industry. Results from both alternative treatments are compared to the Treatment 1 ( $T 1$ hereinafter) representing the status quo of the sector. T1 is based on sessions which implement an industry structure which closely replicates the current status of the IM. The two alternative treatments are inspired on the recommendations by several authors favoring either vertical separation between generators and distributors or independent entry. In fact, the two alternative scenarios have never been compared to each other so far. In Treatment 2 (T2 hereinafter) we implement a market structure in which producers and distributors of electricity are independent entities. In Treatment 3 (T3 hereinafter) we consider a more competitive distribution with a number of small but independent firms entering the downstream distribution market. 
In all our treatments we captured the essence of the market dynamics by focusing on the four common price auctions that generate electricity prices in Spain. As our main scope is to analyze the effects on market prices caused by the introduction of competition in the bidding system generators were chosen by human subjects whereas the technological side of production was simulated according to the data on Spanish generator firms. Final demand conditions were also simulated using data from the Spanish electricity market. In T1 every market included ten firms. Half of them sell electricity to the market whereas the remaining five distribute electricity to final consumers. Table 1 summarizes the main features of the other two treatments relative to our baseline.

\begin{tabular}{|c|c|c|c|}
\hline & T1 & T2 & T3 \\
\hline \# of producers & 5 & 5 & 5 \\
\hline \# of sellers & 5 & 5 & 7 \\
\hline Vertical teams & Yes & No & Yes \\
\hline \# of markets & 5 & 5 & 5 \\
\hline \# of sessions & 1 & 1 & 1 \\
\hline
\end{tabular}

In T1 all participants participated in teams made up of one generator and one distributor. Earnings were equally divided among each team's members at the end of the experiment. In the other two experimental treatments, as competition was introduced by breaking the vertical linkages between firms, subjects were paid on a purely individual basis. We used a between-subject design, as each participant faced only one environment and one condition. Participants were assigned to one market side at random and played a finitely repeated (32 rounds) game with fixed roles. Rounds reproduced the seasonal conditions of demand and production by a sequence of seasons.

Sessions were run at the LINEEX computer lab of the University of Valencia. We gathered data from fifty (sixty in T3) firms for each treatment, grouped in five markets. Every treatment was run in a single session as the number of available computers in LINEEX's main room is 64.

Subjects were recruited among the graduate and undergraduate student population of the University of Valencia and the graduate population at the Technical University of Valencia. In the former, we recruited among economics and business graduate and undergraduate students with at least intermediate knowledge of industrial organization. In the latter, only graduate students from the School of Industrial Engineers were allowed to participate in the experiment. The recruitment procedures were the standard ones in Valencia. Students received an e-mail message announcing sessions. Subjects were only allowed to participate in a single session.

At the beginning of each session the experimenter read aloud the instructions and subjects asked as many questions as they wish. All questions were answered publicly by the experimenter. Before beginning to play, all subjects were asked to complete a short quiz on the payoffs and the rules of the experiment. ${ }^{10}$

Subjects knew in advance that there would be a total of 32 rounds and that the demand condition would change depending on seasonal market conditions. The cost of a power supply

\footnotetext{
10 The full text for the instructions and quiz are available from the authors upon request.
} 
interruption was also known in advance. Table 2 describes weather conditions, hydraulicity and daily phases by each period.

\begin{tabular}{|c|c|c|c|c|c|}
\hline $\begin{array}{l}\text { Year 1, } \\
\text { Period }\end{array}$ & $\begin{array}{c}\text { Season } \\
\text { (conditions) }\end{array}$ & $\begin{array}{l}\text { Daily } \\
\text { phase }\end{array}$ & $\begin{array}{l}\text { Year 2, } \\
\text { Period }\end{array}$ & $\begin{array}{c}\text { Season } \\
\text { (conditions) }\end{array}$ & $\begin{array}{l}\text { Daily } \\
\text { phase }\end{array}$ \\
\hline 1 & $\begin{array}{l}\text { Winter } \\
(\mathrm{D}, \mathrm{N}) \\
\end{array}$ & $1, \mathrm{v}$ & 17 & $\begin{array}{l}\text { Winter } \\
(\mathrm{H}, \mathrm{N})\end{array}$ & $17, v$ \\
\hline 2 & $\begin{array}{l}\text { Winter } \\
(D, N)\end{array}$ & $2, s$ & 18 & $\begin{array}{l}\text { Winter } \\
(\mathrm{H}, \mathrm{N})\end{array}$ & $18, \mathrm{~s}$ \\
\hline 3 & $\begin{array}{l}\text { Winter } \\
(D, C)\end{array}$ & $3, p$ & 19 & $\begin{array}{l}\text { Winter } \\
(\mathrm{H}, \mathrm{C})\end{array}$ & $19, p$ \\
\hline 4 & $\begin{array}{l}\text { Winter } \\
(D, N)\end{array}$ & $4, e$ & 20 & $\begin{array}{l}\text { Winter } \\
(\mathrm{H}, \mathrm{N})\end{array}$ & $20, e$ \\
\hline 5 & $\begin{array}{l}\text { Spring } \\
(\mathrm{H}, \mathrm{N})\end{array}$ & $5, v$ & 21 & $\begin{array}{l}\text { Spring } \\
(\mathrm{H}, \mathrm{N})\end{array}$ & $21, v$ \\
\hline 6 & $\begin{array}{l}\text { Spring } \\
(\mathrm{H}, \mathrm{N})\end{array}$ & $6, s$ & 22 & $\begin{array}{l}\text { Spring } \\
(\mathrm{H}, \mathrm{N})\end{array}$ & $22, s$ \\
\hline 7 & $\begin{array}{l}\text { Spring } \\
(\mathrm{H}, \mathrm{N})\end{array}$ & $7, p$ & 23 & $\begin{array}{l}\text { Spring } \\
(\mathrm{H}, \mathrm{N})\end{array}$ & $23, p$ \\
\hline 8 & $\begin{array}{l}\text { Spring } \\
(\mathrm{H}, \mathrm{N})\end{array}$ & $8, e$ & 24 & $\begin{array}{l}\text { Spring } \\
(\mathrm{H}, \mathrm{N})\end{array}$ & $24, e$ \\
\hline 9 & $\begin{array}{l}\text { Summer } \\
(D, N)\end{array}$ & $9, v$ & 25 & $\begin{array}{l}\text { Summer } \\
(D, N)\end{array}$ & $25, v$ \\
\hline 10 & $\begin{array}{l}\text { Summer } \\
(D, N)\end{array}$ & $10, s$ & 26 & $\begin{array}{l}\text { Summer } \\
(D, N)\end{array}$ & $26, s$ \\
\hline 11 & $\begin{array}{c}\text { Summer } \\
(D, H)\end{array}$ & $11, p$ & 27 & $\begin{array}{c}\text { Summer } \\
(D, H)\end{array}$ & $27, p$ \\
\hline 12 & $\begin{array}{c}\text { Summer } \\
(D, N)\end{array}$ & $12, \mathrm{e}$ & 28 & $\begin{array}{l}\text { Summer } \\
(\mathrm{D}, \mathrm{N})\end{array}$ & $28, \mathrm{e}$ \\
\hline 13 & $\begin{array}{l}\text { Autumn } \\
(\mathrm{D}, \mathrm{N})\end{array}$ & $13, v$ & 29 & $\begin{array}{l}\text { Autumn } \\
(\mathrm{D}, \mathrm{N})\end{array}$ & $29, v$ \\
\hline 14 & $\begin{array}{l}\text { Autumn } \\
(\mathrm{D}, \mathrm{N})\end{array}$ & $14, \mathrm{~s}$ & 30 & $\begin{array}{c}\text { Autumn } \\
(\mathrm{D}, \mathrm{N})\end{array}$ & $30, s$ \\
\hline 15 & $\begin{array}{l}\text { Autumn } \\
(\mathrm{D}, \mathrm{N})\end{array}$ & $15, p$ & 31 & $\begin{array}{l}\text { Autumn } \\
(\mathrm{D}, \mathrm{N})\end{array}$ & $31, p$ \\
\hline 16 & $\begin{array}{l}\text { Autumn } \\
(\mathrm{D}, \mathrm{N})\end{array}$ & $16, \mathrm{e}$ & 32 & $\begin{array}{l}\text { Autumn } \\
(\mathrm{D}, \mathrm{N})\end{array}$ & $32, \mathrm{e}$ \\
\hline
\end{tabular}

Hydraulic Conditions: $(\mathrm{D}, \mathrm{H})=($ Dry, Humid $)$, Weather Conditions: $(\mathrm{C}, \mathrm{H})=($ Cold, Hot $)$.

Daily phases: v=Valley; s=Semi-valley; $\mathrm{p}=$ Peak; e=Extreme Peak.

Rather than using abstract terminology we employ a rather naturalistic corporate context. For example, generator firms were explicitly referred to as "producers" and distributor firms as "sellers". They were told to run a "firm" (or being part of a holding of firms in T1). We avoided the use of terms with what we considered strong connotations. For example, when being part of a team, subjects were not asked to cooperate (or fight) between them. They had no information about the rest of the treatments run in the experiment and we did our best to minimize contamination from information conveyed between subjects participating in different sessions, although we believe that this was not a major issue due to the complexity of our design.

The instructions stressed their individual roles in the experiment. Moreover, the meaning of bids and offers was carefully explained to them as well as the relevance of seasonality and production technologies. For experimenters who are used to worrying about repeated game effects, the use of fixed groups may seem like a strange design choice. However, the field settings that we are interested in simulating involve repeated interactions among the same agents. Repeated game 
effects and history dependence are presumably quite natural in these settings. In fact, in the SEM generator and distributor firms have access to market results with 24 hours delay. ${ }^{11}$

In each round all participants had to simultaneously submit their bids and offers for electricity. The screen on which subjects made their decisions displayed information about production costs (final demand) for generators (distributors). The $P M{ }^{\circledR}$ software was developed from scratch using Java language. Figures 9 and 10 in the Appendix 1 are screen shots from this software. Both figures show the complex information available to subjects before and after they made their decisions. Once their bids and offers were submitted, the software computed demand and supply functions and the four market prices. Firm's payoffs were computed according to each firm buyer (seller) constraints. Figure 1 shows a sample output of the information shown to each participant after the market clearance (1.a) and a real screen shot fitted by the Spanish Market operator OMEL (1.b).
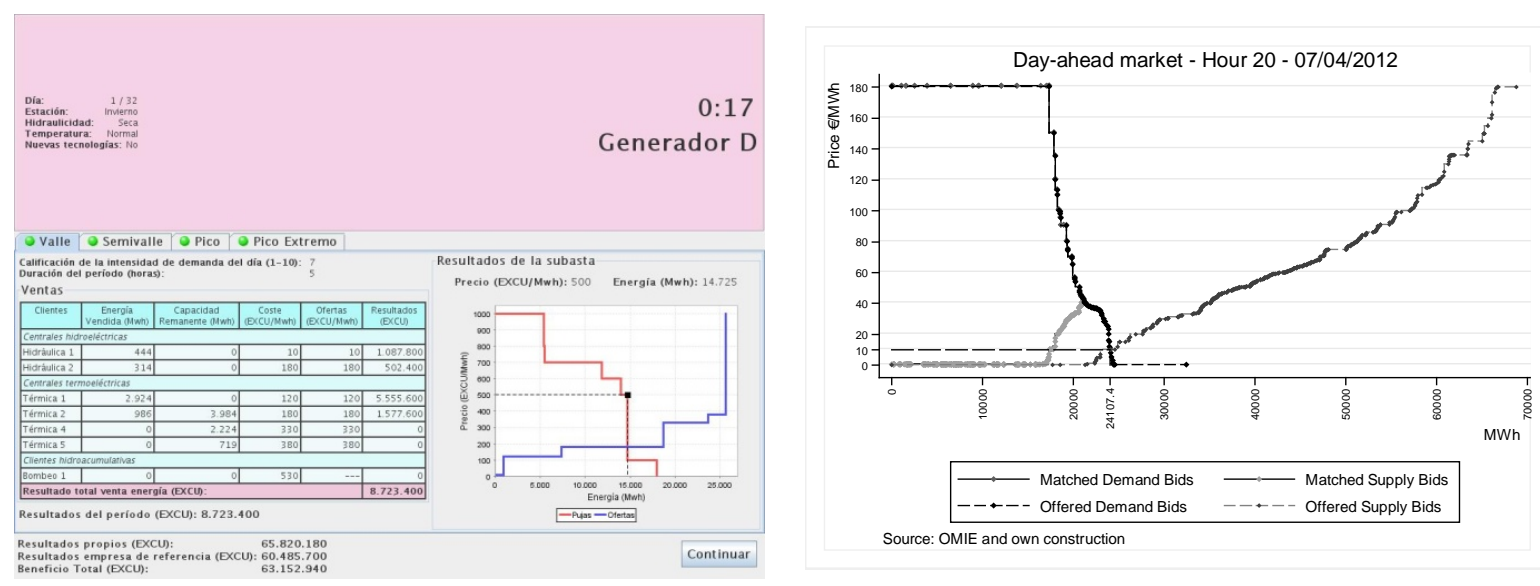

Figure 1: Market clearance at the experiment and a real OMIE market result.

Separate windows on the feedback screen showed firms' results for each market at the aggregate level. In all rounds, subjects had full information about their own costs and profits, and market prices coming from each demand profile. Information about the profit level of all other participants remained unknown to them. Moreover, they had no information from other markets in the same session.

At the end of the session, each subject was paid in cash for all rounds played plus a showup fee of five Euros. Payments took place on an individual and private basis. Recall that all payoffs are in "ECUs" (experimental currency units) which were converted to Euros. The average total payoff was $95.29 €$ and the average session lasted about 150 minutes (another 60 minutes were used to explain the instructions and run the quiz). These earnings were sufficiently large to generate a good supply of subjects and compensate them for such a long instruction and play time.

\footnotetext{
${ }^{11}$ At the web page of the market operator OMEL (www.omelholding.es) market results are available for anyone visiting the site.
} 


\section{Results}

In this section, we present the results obtained from the experimental framework described above. We run 17 independent experimental markets: 6 under T1, 6 under T2 and 5 under T3. In the following Subsection 3.1 we proceed with the descriptive analysis. The discussion is based on the evolution of price averages by period over 32 periods, as illustrated in Figures 2 to 8 . In particular, Figures 2 to 4 are constructed to compare for each treatment price averages across the four different demand daily phases. Figures 5 to 8 describe differences for each demand daily phase across treatments.

In Subsection 3.2 we perform a formal statistical and econometric analysis. A Kolmogorov-Smirnov (KS) equality-of-distribution test and a Differences-in-Differences econometrical approach are conducted to test the robustness of the results.

\subsection{Descriptive statistics and figures}

We first focus on the effect that the two market organization alternatives have on price averages by demand daily phases. This is done for each treatment. Descriptive statistics are reported in Table 3. We also plotted the path of price averages across periods in Figures 2 to 4 . These comparisons are intended to test the consistency of our experimental results. Thus, one would expect that the price averages of electricity at valley hours is lower than the price at semi-valley hours, which in turn should be lower than the price at peak hours, and finally this should be lower than the price at extreme peak hours. Summary statistics are presented in Table 3 (standard deviations in parentheses) to show how results are consistent with how players were expected to behave. We separate information by treatment and demand profile. Figures 2 to 4 plot price averages by periods.

Generally speaking, both our working hypotheses receive some support by our data, as can be seen in each one of the Figures 2 to 4 . However, Table 3 reveals that if we concentrate on the differences between "Semi-Valley" and "Peak" prices, we see that the aforementioned general picture becomes less clear and the inverse ranking than that implied by our hypotheses is obtained in some cases. On the contrary, "Extreme Peak" and "Valley" prices are, respectively, the highest and the lowest in all periods of the experiment in all treatments, which implies a strong confirmation of the hypothesis that our design yields meaningful responses to the implemented daily fluctuations of demand. 


\begin{tabular}{|l|c|c|c|}
\hline \multicolumn{5}{|c|}{ TABLE 3 Average prices by treatment } \\
\hline & T1 & T2 & T3 \\
\hline \multirow{2}{*}{ pv } & 339.8 & 311.6 & 311.4 \\
& $(51.3)$ & $(51.4)$ & $(57)$ \\
\hline \multirow{2}{*}{ ps } & 353 & 353.9 & 334.2 \\
& $(48.8)$ & $(39.2)$ & $(59.1)$ \\
\hline \multirow{2}{*}{ pp } & 366 & 361.5 & 341 \\
& $(57.4)$ & $(37.5)$ & $(63.5)$ \\
\hline \multirow{2}{*}{ pe } & 397 & 386.2 & 369.5 \\
& $(44.3)$ & $(44.5)$ & $(68.8)$ \\
\hline
\end{tabular}
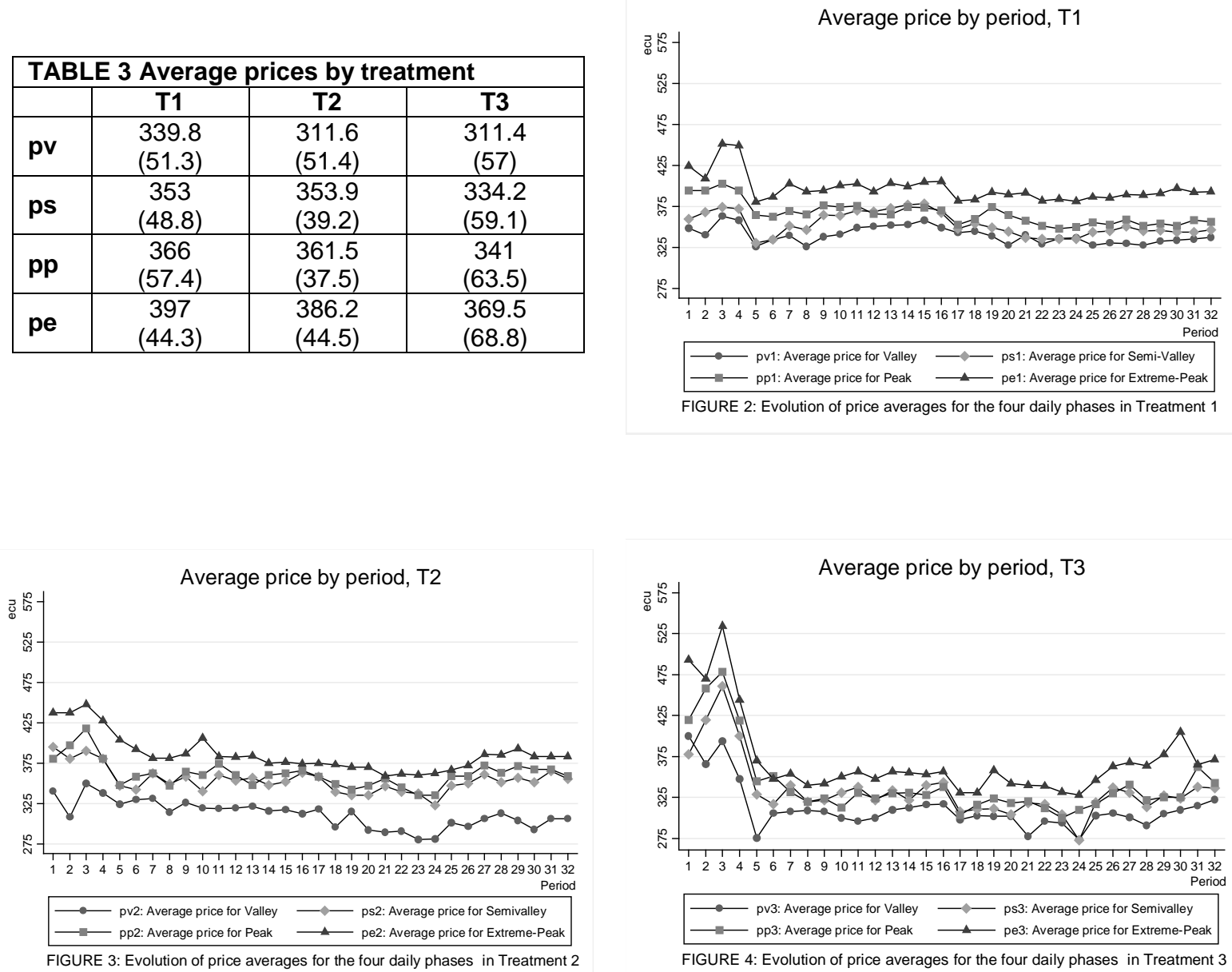

As shown in Table 3, on average, valley prices are the highest under T1 with no mean differences between semi-valley and peak prices under T1 and T2. Thus, introducing unbundling between upstream and downstream activities does not seem to be the most efficient way of enhancing competition. When more independent distributors are allowed to operate in the market, the results change. An increase in downstream competition has a pro-competitive effect not only during valleys, but also guarantees lower prices also during semi-valley, peak and extreme peak hours.

Let us have a more detailed look at these insights from Figures 2 to 4 . A main feature across the three treatments is that experimental subjects behave more competitively after exactly 5 rounds, whatever the demand profile considered. This is consistent with most of the experiments on oligopolistic markets where individuals take some rounds in order to learn how the market works. The fact that some subjects earn almost zero profits induce a more competitive behavior that yields lower prices after one or two rounds of high prices.

T2 reveals that unbundling per se does not necessarily enhance competition. In fact, only average prices for extreme peak and valley are clearly lower than in T1. For peak and semi-valley demand profiles average prices are quite similar. The reason is that experimental subjects tacitly coordinate their bidding behavior to some extent. This observation resembles the situation in the 
SEM, where unbundling generation and distribution activities does not yield a more competitive behavior in the pool.

An increase of competitors on the demand side of electricity markets organized as pools has been a recommendation of the European Competition Authorities for all country members since late 90's. We deal with this scenario in T3. Overall, we find that T3 is more competitive than T1 and T2. Indeed, for each demand profile price averages are lower than in the other treatments but also the variability is reduced. Moreover, differences across different demand profiles are minimized. This is because downstream competition induces a more aggressive bidding in order to catch demand. This behavior also has a pro-competitive effect on the generators' bidding behavior.
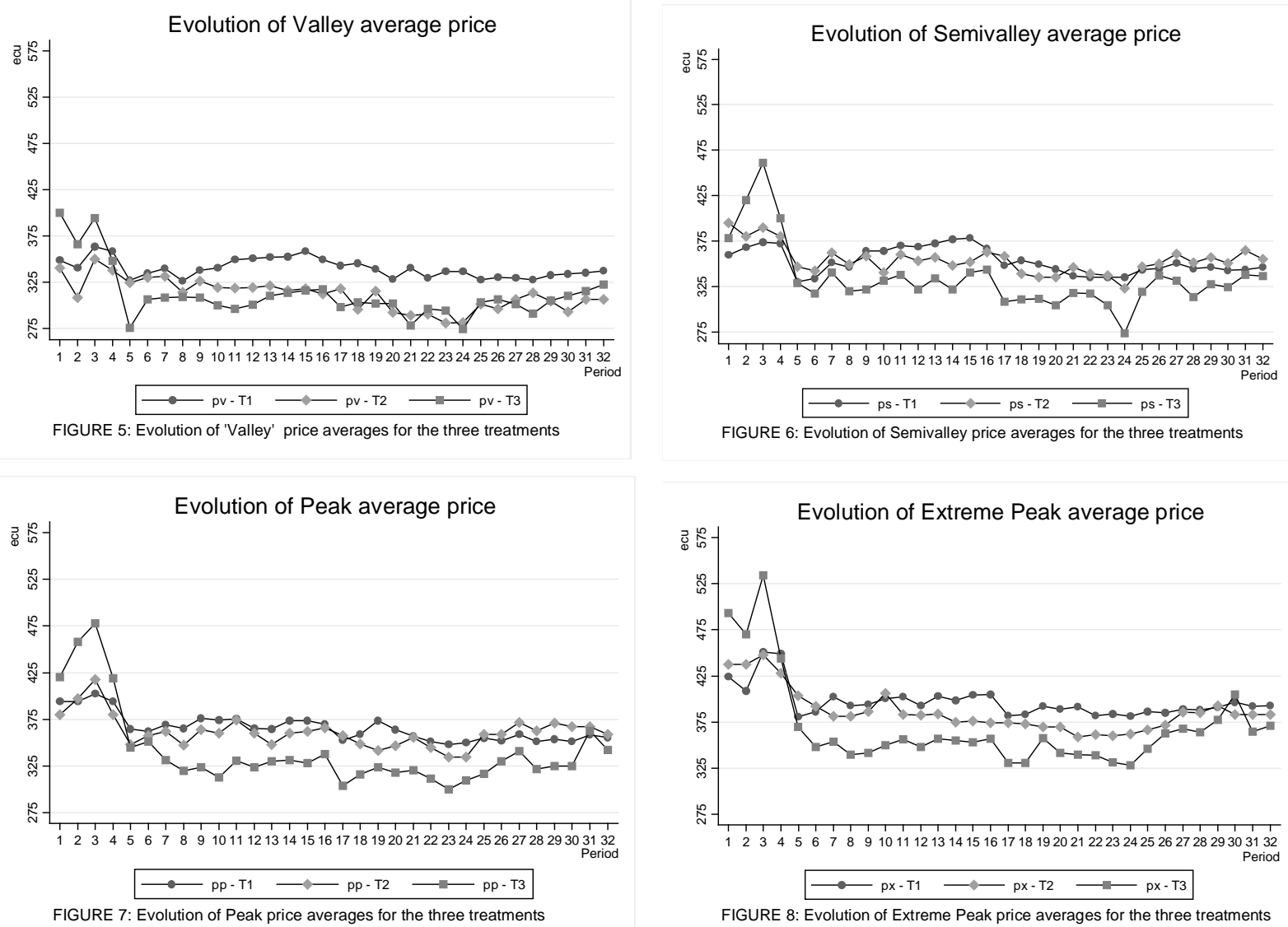

Figures 5 to 8 compare price averages across treatments for each demand profile. Concerning Valley prices, Figure 5 indicates that both vertical separation (T2) and independent entry (T3) in the market for electricity distribution would reduce prices as compared to the status quo (T1). However, at a first glance it is not clear which of the alternative treatments yields lower prices. This can be due to the fact that the amount of energy traded is small so that T2 and T3 do not provide sufficient evidence of competitive improvements. That is, as long as a small amount of energy is traded, the opportunity of increasing revenues by bidding more aggressively is reduced. Thus, although prices are lower than in T1, the competitive effects of unbundling (T2) and increasing downstream competition (T3) are very mall. 
Regarding the prices of the Semi-Valley phase, Figure 6 suggests that the two alternative market structures proposed here have a moderate effect on prices as compared to T1. More specifically, only $\mathrm{T} 3$, the independent entry alternative, seems to have a clear effect on prices. In this case, prices are systematically, although moderately, lower than in the other two treatments. On the contrary, vertical separation is not found to have any clear competition-enhancing effect on the prices of this demand phase. Figure 7 indicates a similar pattern for Peak prices. Independent entry in the distribution of electricity lowers prices, but less than in the case of what was found in the case of the Semi-Valley phase. Like in the previous case, vertical separation leads to prices which are not significantly different from those obtained in the baseline treatment for the same demand phase. Figure 8 reveals that in the case of Extreme-Peak hours T3 yields to lower prices.

Therefore, our results indicate that both structural changes considered here would lead to lower prices for electric energy. However, independent entry into the market of electric energy distribution is found to be systematically more effective than vertical separation. Another interesting aspect of our results relates with a key feature which has not been studied so far, but constitutes a central concern of policy makers regarding the function of the electricity market. Indeed, our data contains information on seasonality, hydroelectric resources, temperature and availability of new technologies. ${ }^{12}$ The effects of these variables on prices are tested.

If the weather is dry, hydroelectric generation cannot be used to cover base load demand because the opportunity cost of water usage is very high. Therefore, generation comes from fossil fuels, which have a higher variable cost. Interestingly, cold waves are more price-rocketing than heat waves. The shape of the demand curve may be the reason of this behavior. We may observe more electricity is consumed during cold waves (heating) than during heat waves (cooling). Once again learning makes a difference during extreme peak hours under T2 and during cold waves.

Finally, we can observe a phenomenon which has not been reported elsewhere so far. Note that the entry of new firms in the market for electricity market distribution increases the incentives of both downstream and upstream agents to use supply interruptions as a strategic weapon signaling their bargaining strength. However, interestingly, the vertical separation treatment (in which producers and distributors of electricity are independent from each other) yields the lowest number of supply interruptions, which indicates that it is the presence of vertical relations among incumbents that triggers the "interruption wars" reported here.

\footnotetext{
12 Tables 6 to 8 in Appendix 3 report prices and standard deviations for hydraulicity, temperature, and seasonality, respectively.
} 


\subsection{Statistical and econometric analysis}

In order to test the robustness of the results presented in the previous subsection we conduct here a statistical and econometric analysis of the experimental data. We first report the results from a Kolmogorov-Smirnov (KS) equality-of-distribution test in order to highlight the significance of distributional differences across treatments. This test is based on comparisons between pairs of distributions. The directional hypotheses are evaluated with the statistics

$$
\mathrm{KS}^{+}=\max _{\mathrm{x}}\left\{\mathrm{P}^{\mathrm{h}}(\mathrm{x})-\mathrm{P}^{\mathrm{k}}(\mathrm{x})\right\} \text { and } \mathrm{KS}^{-}=\min _{\mathrm{x}}\left\{\mathrm{P}^{\mathrm{h}}(\mathrm{x})-\mathrm{P}^{\mathrm{k}}(\mathrm{x})\right\}
$$

where $\mathrm{P}^{\mathrm{h}}(\mathrm{x})$ and $\mathrm{P}^{\mathrm{k}}(\mathrm{x})$ are the empirical distribution functions for the two sample groups respectively, $h, k=1,2,3$ and $h \square k$. The combined statistic is simply

$$
K S=\max \left(\left|K S^{+}\right|,\left|K S^{-}\right|\right) \cdot{ }^{13}
$$

We first do a Kernel density plot of prices by treatment. Results of the test are reported in Table 4. It is apparent that prices across treatments do not have the same distribution. Thus, the null hypothesis of equality of the distributions of prices under different treatments is rejected. As a result, it seems reasonable that the characteristics of each treatment have a non negligible impact

\begin{tabular}{|c|c|c|c|c|c|c|}
\hline & \multicolumn{2}{|c|}{ TR1 and TR2 } & \multicolumn{2}{|c|}{ TR1 and TR3 } & \multicolumn{2}{|c|}{ TR2 and TR3 } \\
\hline & KS & p-value & KS & p-value & KS & $p$-value \\
\hline pv & 0.4000 & 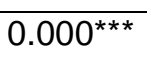 & 0.5247 & $0.000 * \star \star$ & 0.1747 & $0.012^{\star \star}$ \\
\hline ps & 0.2188 & $0.001^{* * *}$ & 0.3979 & $0.000 * \star \star$ & 0.4016 & $0.000 * \star *$ \\
\hline pp & 0.3312 & $0.000 * \star *$ & 0.4346 & $0.000^{\star \star \star}$ & 0.4784 & $0.000^{\star \star \star}$ \\
\hline pe & 0.2437 & $0.000 * \star \star$ & 0.4413 & $0.000 * \star \star$ & 0.3553 & $0.000 * * *$ \\
\hline p & 0.2375 & $0.000 * * *$ & 0.3890 & $0.000^{* \star *}$ & 0.3073 & $0.000 \star \star \star *$ \\
\hline
\end{tabular}
on the prices observed.

\footnotetext{
${ }^{13}$ The $\mathrm{p}$-value for KS is obtained using the asymptotic limiting distribution. Let $\mathrm{m}$ and $\mathrm{n}$ be the sample sizes for each group. Then, Smirnov (1939) shows that $\lim _{n, m \rightarrow \infty} \operatorname{Pr}\left\{\sqrt{\frac{m n}{(m+n)}} K S_{m, n} \leq z\right\}=1-2 \sum_{i=1}^{\infty}(-1)^{i-1} \exp \left(-2 i^{2} z^{2}\right)$.
} 
Second, we test some hypotheses on the effects of the treatments on valley, semi-valley, peak and extreme-peak prices under the three different scenarios of weather forecast and seasonality. As experimental subjects have been working under a vertically-integrated market structure, a vertically-separated market structure, and facing new entrants on the demand side of the market, we have three different groups which are affected by several exogenous characteristics.

We consider a Differences-in-Differences approach (DiD hereinafter) to measure the effect of the treatments on market results. ${ }^{14}$ In our case, DiD is an econometric technique whose basic premise is to examine the effect of a treatment by comparison with the control treatment group. The approach assumes that all other factors affected identically both groups under comparison. For it to provide consistent estimations, we must assume that the two groups do not change over the course of the treatment. Thus, in our experiment these conditions hold, since all the factors that affect generators and distributors are not dependent on the treatment under study. Besides, subjects are the same during the course of the experiment.

We take $\mathrm{T} 1$ as our control group. The coefficient of the interaction variable for $\mathrm{T} 2\left(T R_{2}\right)$ is $\mathrm{Q}$ and for $\mathrm{T} 3\left(T R_{3}\right)$ is $\mathrm{D}$. The following regression equation where the endogenous variable is the price $P_{t}$ has been run,

$$
P=\alpha_{0}+\theta T R_{2, t}+\eta \mathrm{TR}_{3, \mathrm{t}}+\alpha_{1} D_{t}+\alpha_{2} S_{t}+\alpha_{3} Z_{t}+\varepsilon_{t}
$$

where $D$ is a dummy vector that controls for within-day variations in demand, $S$ is a dummy vector that controls for seasonal variations (winter, spring, summer and autumn) and $Z$ is a dummy vector that controls for weather conditions (normal, cold-wave and heat-wave). ${ }^{15}$

Once we control for seasonal as well as daily variations, any difference in market results can be attributed to variations in the strategic bidding behavior after the new market structure is in place (namely from T1 to T2 and from T1 to T3). The error term contains all the demand and supply shocks that are uncorrelated with regressors. Thus, if $0<0(>0)$ prices under T2 are significantly lower (higher) than those under the status quo after controlling for common factors such as demand fluctuations and considering unexpected shocks that cannot be anticipated by market operators. Whereas, if $\square<0(>0)$, prices under T3 are significantly lower (higher) than those under the status quo. Finally, the difference between treatments can be estimated through the difference in the parameters, Q - : .

Estimation results are reported in Table 5 . The base group corresponds to extreme prices under T1 in autumn, with dry weather and heat-wave. Moreover, estimation results are not sensitive to this choice. In viewing Table 5 it is observed that the DiD analysis confirms the statistical analysis preceding this section. Prices under T2 and T3 are significantly lower as compared to the baseline

\footnotetext{
${ }^{14}$ See Ashenfelter and Card (1985) for early work on this type of estimation and Abadie (2005) for extensions.

${ }^{15}$ In Appendix 3 we show how indeed $\mathrm{Q}$ and $\mathrm{Q}$ are the coefficients of interest to measure differences in market structure.
} 
at T1. Besides, the difference between T2 and T3 measured by $\mathrm{T}-\mathrm{T}$ is equal to -14.96 and it is also significant. Thus, our results show how allowing entry of new distributors in the market without breaking the vertical structure of the system would be sufficient to yield lower prices in the market.

\begin{tabular}{|c|c|}
\hline \multicolumn{2}{|c|}{ TABLE 5.- DiD in prices } \\
\hline 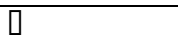 & $-10.64^{\star \star \star}$ \\
\hline 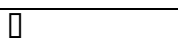 & $-24.90 * \star \star$ \\
\hline Valley & $-63.32^{\star \star \star}$ \\
\hline Semi-valley & $-37.20^{\star \star \star}$ \\
\hline Peak & $-28.03^{\star \star \star}$ \\
\hline Winter & $46.12^{\star \star \star}$ \\
\hline Spring & $49.52^{\star \star \star}$ \\
\hline Summer & -6.03 \\
\hline Humid & $-62.69^{\star \star \star}$ \\
\hline Normal & -6.21 \\
\hline Cold-wave & 9.45 \\
\hline Constant & $369.88^{\star \star *}$ \\
\hline $\mathrm{R}^{2}$ & 0.4991 \\
\hline $\mathrm{F}(8,1895)$ & $41.15^{\star \star \star}$ \\
\hline
\end{tabular}

Generally speaking, these estimations provide a rigorous test confirming the findings reported in the previous section. Furthermore, it is confirmed that our experimental setting leads previously uninformed subjects to actions which induce quite realistic market outcomes reflecting what would have been expected to happen under each type of consumption time and each specific weather condition. An additional finding is that weather conditions have a stronger and statistically significant effect on output than prices.

\section{Conclusions}

Many experts have suggested restructuring the SEM. However, due to the complexity of the market, textbook industrial organization tells us little on the direction that such restructuring should follow. Even sophisticated theoretical models systematically fail to address a number of central features of the real-world case under study. Furthermore, given the fact that historical data cannot be used to infer anything on the effects of a given structural change, empirical research would also fail to address the issue of what we should expect to observe following a change in the current structure of the market.

We have reported here results from a series of experiments designed to address the effects of two alternative structural changes: vertical separation of corporations which are active on both 
sides of the market (generation and distribution) and independent entry of firms in the market of electric energy distribution.

Our results indicate that both measures would lead to lower prices, although independent entry in the distribution sector would yield more significant price decreases. However, this is achieved at some cost, as it would increase the number of supply interruptions. Breaking the vertical links between producers and distributors would lead to much more moderate price decreases, but this would be combined by a decrease in the number of supply interruptions.

Policy makers need to be assisted by research instruments and methodologies which are appropriate for addressing some central features of the real world market under study, like demand fluctuations, production and demand-side asymmetries and exercise of market power through implicit recognition of strategic interdependences. Such objectives are more likely to be achieved by appropriately designed and conducted laboratory experiments with more realistic and, thus, complex settings, of which this is a first attempt.

Hopefully, our results will contribute to fill the gap between theoretical results based mainly on simple, abstract, symmetric setups and a complex reality with asymmetric producers and distributors facing a complex and uncertain economic system of supply and demand conditions. 
APPENDIX 1: Software interface.

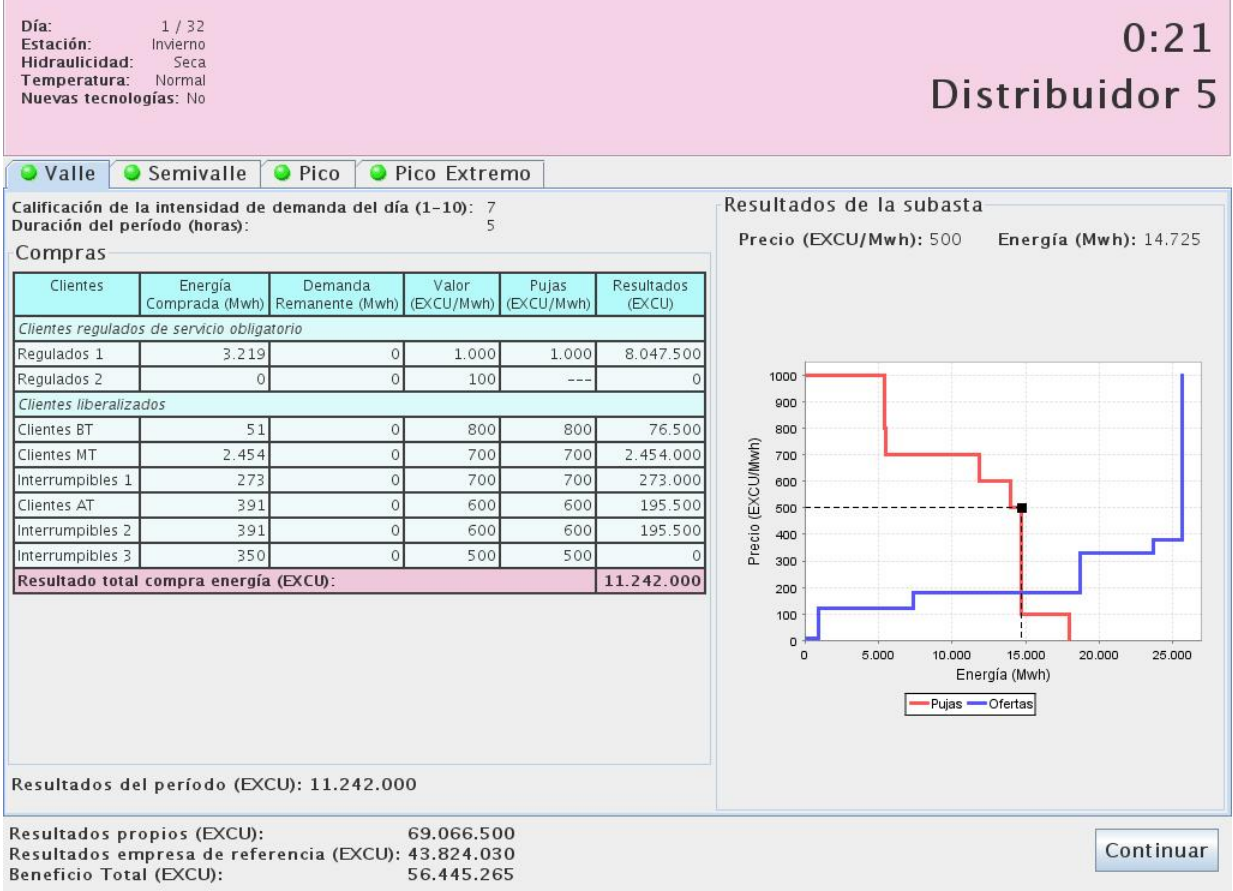

Figure 9: Strategy-submission and feedback interface for a distributor.

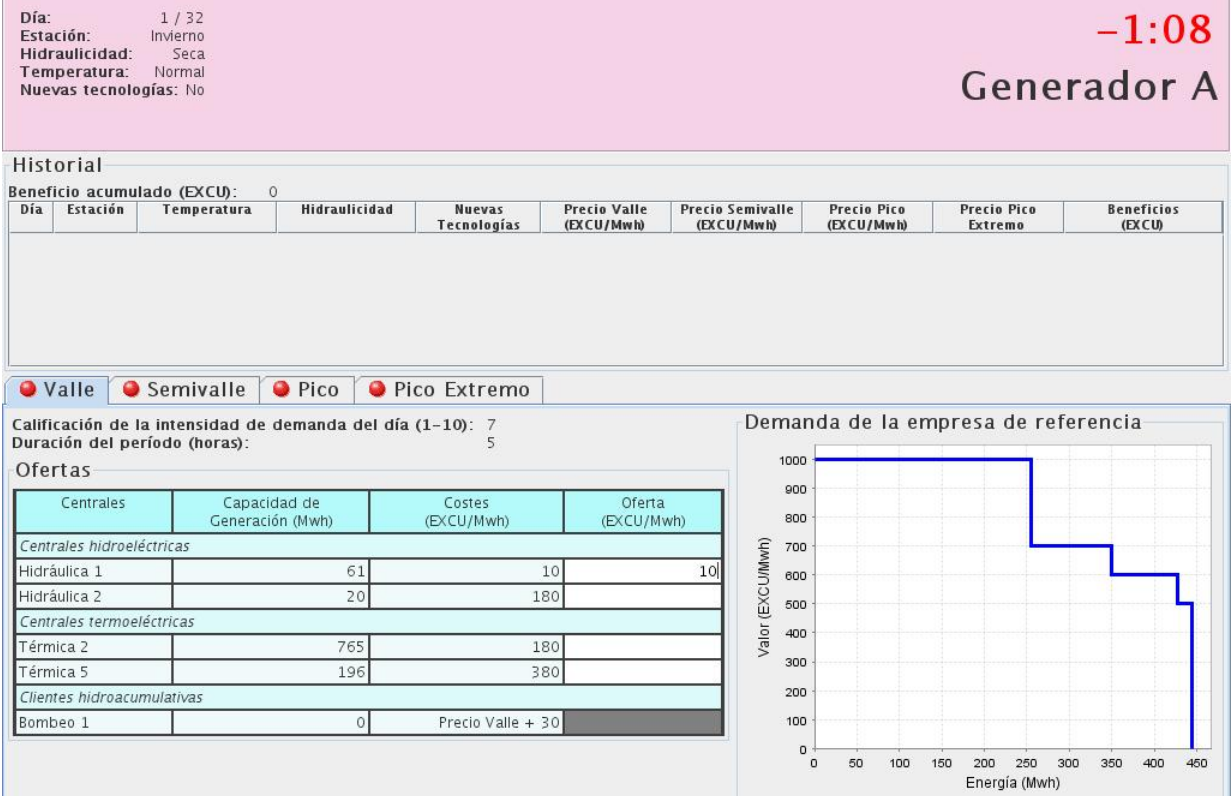

Continuar

Figure 10: Strategy-submission and feedback interface for a producer. 


\section{APPENDIX 2: Differences-in-differences procedure.}

The DiD approach consists of the following procedure. Estimate the regression equation [1] using Ordinary Least Squares. By calculating the following expected prices

$$
\begin{gathered}
E\left(P / T R_{2}=1, T R_{3}=0\right)=\alpha_{0}+\theta+\alpha_{1}+\alpha_{2}+\alpha_{3}, \\
E\left(P / T R_{2}=0, T R_{3}=1\right)=\alpha_{0}+\eta+\alpha_{1}+\alpha_{2}+\alpha_{3}, \\
E\left(P / T R_{2}=0, T R_{3}=0\right)=\alpha_{0}+\alpha_{1}+\alpha_{2}+\alpha_{3},
\end{gathered}
$$

the DiD consists of subtracting expected prices under the status quo (T1) from those under each alternative treatment (T2 and T3),

$$
\begin{aligned}
& E\left(P / T R_{2}=1, T R_{3}=0\right)-E\left(P / T R_{2}=0, T R_{3}=0\right)=\theta, \\
& E\left(P / T R_{2}=0, T R_{3}=1\right)-E\left(P / T R_{2}=0, T R_{3}=0\right)=\eta .
\end{aligned}
$$

\begin{tabular}{|c|c|c|c|c|}
\hline \multicolumn{2}{|c|}{ TABLE 6. Average } & T1 & T2 & T3 \\
\hline \multirow[t]{4}{*}{ Dry } & pv & $\begin{array}{l}342.6 \\
(48.9)\end{array}$ & $\begin{array}{l}315.5 \\
(50.8)\end{array}$ & $\begin{array}{l}321.4 \\
(59.1)\end{array}$ \\
\hline & ps & $\begin{array}{l}359.8 \\
(45.9) \\
\end{array}$ & $\begin{array}{l}360.6 \\
(36.2) \\
\end{array}$ & $\begin{array}{c}347.6 \\
(62)\end{array}$ \\
\hline & $\mathrm{pp}$ & $\begin{array}{l}369.7 \\
(58.8)\end{array}$ & $\begin{array}{l}369.3 \\
(35.1)\end{array}$ & $\begin{array}{l}353.5 \\
(70.5)\end{array}$ \\
\hline & pe & $\begin{array}{l}402.8 \\
(41.4) \\
\end{array}$ & $\begin{array}{l}393.4 \\
(47.2) \\
\end{array}$ & $\begin{array}{l}386.3 \\
(73.9) \\
\end{array}$ \\
\hline \multirow[t]{4}{*}{ Humid } & pv & $\begin{array}{l}335.2 \\
(55.1)\end{array}$ & $\begin{array}{c}305 \\
(52.1)\end{array}$ & $\begin{array}{l}295.5 \\
(49.6)\end{array}$ \\
\hline & ps & $\begin{array}{l}341.5 \\
(51.6) \\
\end{array}$ & $\begin{array}{l}342.7 \\
(41.6) \\
\end{array}$ & $\begin{array}{c}312.8 \\
(47) \\
\end{array}$ \\
\hline & $\mathrm{pp}$ & $\begin{array}{l}359.8 \\
(54.8)\end{array}$ & $\begin{array}{c}348.5 \\
(38)\end{array}$ & $\begin{array}{l}321 \\
(44)\end{array}$ \\
\hline & pe & $\begin{array}{l}387.1 \\
(47.4)\end{array}$ & $\begin{array}{c}374 \\
(36.8)\end{array}$ & $\begin{array}{l}342.7 \\
(49.4)\end{array}$ \\
\hline
\end{tabular}

As a result, it is easy to show how differences between treatments are just $\square-\square$.

APPENDIX 3: Average prices by hydraulicity, temperature, and seasonality.

Table 6 summarizes results considering periods of dry versus humid climate. If the weather is dry it means hydroelectric generation cannot be used to cover demand because the opportunity cost of water usage is very high. Therefore, generation comes from fossil fuels, which have a higher variable cost. As a result, the experiment shows how prices are on average higher. But, notice how under stage treatments 2 and 3, prices tend to converge and are actually rather high. This may arise as a result of learning during the bidding process. 


\begin{tabular}{|c|c|c|c|c|}
\hline & & T1 & T2 & T3 \\
\hline \multirow[t]{4}{*}{ Normal } & pv & $\begin{array}{l}339.1 \\
(52.1) \\
\end{array}$ & $\begin{array}{c}310 \\
(51.5) \\
\end{array}$ & $\begin{array}{l}309.7 \\
(55.2)\end{array}$ \\
\hline & ps & $\begin{array}{l}351.8 \\
(49.1)\end{array}$ & $\begin{array}{l}352.8 \\
(39.1)\end{array}$ & $\begin{array}{c}330.3 \\
(53)\end{array}$ \\
\hline & $\mathrm{pp}$ & $\begin{array}{l}364.4 \\
(57.1)\end{array}$ & $\begin{array}{l}359.4 \\
(36.2)\end{array}$ & $\begin{array}{c}337 \\
(57.9)\end{array}$ \\
\hline & pe & $\begin{array}{l}395.3 \\
(43.6)\end{array}$ & $\begin{array}{l}384.6 \\
(42.7)\end{array}$ & $\begin{array}{l}364.4 \\
(61.9)\end{array}$ \\
\hline \multirow[t]{4}{*}{$\begin{array}{l}\text { Heat } \\
\text { Wave }\end{array}$} & pv & $\begin{array}{c}339.3 \\
(51)\end{array}$ & $\begin{array}{l}312.2 \\
(49.7) \\
\end{array}$ & $\begin{array}{l}298.5 \\
(39.7) \\
\end{array}$ \\
\hline & ps & $\begin{array}{l}360.2 \\
(49.2)\end{array}$ & $\begin{array}{l}360.5 \\
(31.5) \\
\end{array}$ & $\begin{array}{l}334.6 \\
(38.5)\end{array}$ \\
\hline & $\mathrm{pp}$ & $\begin{array}{l}367.2 \\
(54.8)\end{array}$ & $\begin{array}{c}373 \\
(28.3)\end{array}$ & $\begin{array}{c}336 \\
(49.2)\end{array}$ \\
\hline & pe & $\begin{array}{l}395.7 \\
(34.5) \\
\end{array}$ & $\begin{array}{c}384.5 \\
(46)\end{array}$ & $\begin{array}{l}362.3 \\
(40.8) \\
\end{array}$ \\
\hline \multirow[t]{4}{*}{$\begin{array}{l}\text { Cold } \\
\text { Wave }\end{array}$} & pv & $\begin{array}{l}350.8 \\
(42.8) \\
\end{array}$ & $\begin{array}{l}332.5 \\
(52.8) \\
\end{array}$ & $\begin{array}{l}348 \\
(83) \\
\end{array}$ \\
\hline & ps & $\begin{array}{l}361.5 \\
(47.7) \\
\end{array}$ & $\begin{array}{l}362.5 \\
(48.9) \\
\end{array}$ & $\begin{array}{c}386.3 \\
(115.2) \\
\end{array}$ \\
\hline & $\mathrm{pp}$ & $\begin{array}{c}388 \\
(65.5) \\
\end{array}$ & $\begin{array}{l}380 \\
(57) \\
\end{array}$ & $\begin{array}{c}401 \\
(111.6) \\
\end{array}$ \\
\hline & pe & $\begin{array}{l}421.6 \\
(57.3)\end{array}$ & $\begin{array}{c}409 \\
(63.7) \\
\end{array}$ & $\begin{array}{c}446 \\
(123.6) \\
\end{array}$ \\
\hline
\end{tabular}

Table 7 presents the results under three different scenarios of weather forecast. Interestingly, cold waves are more prices rocketing than heat waves. The shape of the demand curve may be the reason of this behaviour. Once again learning makes a difference during extreme peak hours under treatment 2 and cold waves.

\begin{tabular}{|c|c|c|c|c|}
\hline \multicolumn{2}{|c|}{ TABLE 8. Averas } & \multirow{2}{*}{$\begin{array}{c}\text { T1 } \\
345.5 \\
(45.2)\end{array}$} & \multirow{2}{*}{$\begin{array}{c}\text { T2 } \\
319.5 \\
(55.9)\end{array}$} & \multirow{2}{*}{$\begin{array}{c}\text { T3 } \\
339.1 \\
(69.6)\end{array}$} \\
\hline Winter & pv & & & \\
\hline & ps & $\begin{array}{l}358.6 \\
(45.5)\end{array}$ & $\begin{array}{c}364.1 \\
(45)\end{array}$ & $\begin{array}{l}361.7 \\
(87.4) \\
\end{array}$ \\
\hline & $\mathrm{pp}$ & $\begin{array}{l}379.2 \\
(64.1)\end{array}$ & $\begin{array}{l}371.4 \\
(43.1)\end{array}$ & $\begin{array}{l}379.6 \\
(89.5) \\
\end{array}$ \\
\hline & pe & $\begin{array}{l}409.9 \\
(55.4)\end{array}$ & $\begin{array}{c}404.7 \\
(52)\end{array}$ & $\begin{array}{l}412.9 \\
(101)\end{array}$ \\
\hline \multirow[t]{4}{*}{ Autumn } & pv & $\begin{array}{l}343.8 \\
(53.8)\end{array}$ & $\begin{array}{l}309.4 \\
(44.1)\end{array}$ & $\begin{array}{l}313.6 \\
(47.9) \\
\end{array}$ \\
\hline & ps & $\begin{array}{c}359.2 \\
(48)\end{array}$ & $\begin{array}{c}356 \\
(34.9)\end{array}$ & $\begin{array}{l}333.4 \\
(38.7)\end{array}$ \\
\hline & $\mathrm{pp}$ & $\begin{array}{l}362.6 \\
(56.2)\end{array}$ & $\begin{array}{l}362.5 \\
(34.7)\end{array}$ & $\begin{array}{l}334.9 \\
(44.2)\end{array}$ \\
\hline & pe & $\begin{array}{l}398.1 \\
(36.1)\end{array}$ & $\begin{array}{l}381.4 \\
(37.7)\end{array}$ & $\begin{array}{c}366.3 \\
(55)\end{array}$ \\
\hline \multirow[t]{4}{*}{ Spring } & pv & $\begin{array}{l}333.5 \\
(57.3)\end{array}$ & $\begin{array}{c}305 \\
(55.1)\end{array}$ & $\begin{array}{l}292.6 \\
(46.3) \\
\end{array}$ \\
\hline & ps & $\begin{array}{l}337.9 \\
(49.3)\end{array}$ & $\begin{array}{c}343.1 \\
(43)\end{array}$ & $\begin{array}{l}314.8 \\
(44.9)\end{array}$ \\
\hline & $\mathrm{pp}$ & $\begin{array}{l}358.5 \\
(49.7)\end{array}$ & $\begin{array}{c}348.3 \\
(40)\end{array}$ & $\begin{array}{c}323.7 \\
(47)\end{array}$ \\
\hline & pe & $\begin{array}{l}387.5 \\
(46.7)\end{array}$ & $\begin{array}{l}375.1 \\
(39.3)\end{array}$ & $\begin{array}{l}343.8 \\
(40.8)\end{array}$ \\
\hline \multirow[t]{4}{*}{ Summer } & pv & $\begin{array}{c}336.4 \\
(49)\end{array}$ & $\begin{array}{l}312.3 \\
(50.6)\end{array}$ & $\begin{array}{l}300.6 \\
(50.6)\end{array}$ \\
\hline & ps & $\begin{array}{l}356.2 \\
(50.7)\end{array}$ & $\begin{array}{l}352.5 \\
(30.5)\end{array}$ & $\begin{array}{l}326.8 \\
(40.6)\end{array}$ \\
\hline & $\mathrm{pp}$ & $\begin{array}{l}363.7 \\
(58.5)\end{array}$ & $\begin{array}{l}363.9 \\
(28.1)\end{array}$ & $\begin{array}{l}325.2 \\
(43.9) \\
\end{array}$ \\
\hline & pe & $\begin{array}{l}392.4 \\
(33.9)\end{array}$ & $\begin{array}{l}383.4 \\
(43.6)\end{array}$ & $\begin{array}{l}354.7 \\
(38.1)\end{array}$ \\
\hline
\end{tabular}




\section{References}

Abadie, A., 2005. Semiparametric Difference in Difference Estimators, Review of Economic Studies 72, 1-19.

Agosti, L., Padilla, A. J., Requejo, A., 2007. El Mercado de Generación Eléctrica en España: Estructura, Funcionamiento y Resultados. Economía Industrial 21-37.

Arocena, P., Kühn, K. U., Regibeau, P. 1999. Regulatory reform in the Spanish electricity industry: a missed opportunity for competition. Energy Policy 27, 387-399.

Ashenfelter, O., Card, D., 1985. Using the Longitudinal Structure of Earnings to Estimate the Effects of Training Programs, Review of Economics and Statistics 67, 648-660.

Brandts, J., Pezanis-Christou, P., Schram, A., 2008. Competition with Forward Contracts: A Laboratory Analysis Motivated by Electricity Market Design, The Economic Journal 118, 192-214.

Ciarreta, A., Gutiérrez-Hita, C., 2006. Supply function versus quantity competition in Supergames, International Journal of Industrial Organization 24(4), 773-783.

Ciarreta, A., Espinosa, M.P., 2009. Supply Function Competition in the Spanish Wholesale Electricity Market, The Energy Journal 4, 137-158

Ciarreta, A., Espinosa, M.P., 2010. Market power in the Spanish electricity auction, Journal of Regulatory Economics 37(1), 42-69.

Directive 96/92/EC of the European Parliament and of the Council of 19 December 1996 concerning common rules for the internal market in electricity.

Ede, S., Mount, T., Schulze, W., Thomas, R., Zimmerman, R., 2001. Experimental Tests of Competitive Markets for Electricity, Proceedings of the $34^{\text {th }}$ Hawaii International Conference on System Sciences.

Fabra, N., 2003. Tacit Collusion in Repeated Auctions: Uniform versus Discriminatory Auctions, Journal of Industrial Economics 51, 271-293.

Fabra, N., von der Fehr, N.-H, Harbord D., 2006a. Designing Electricity Auctions", Rand Journal of Economics 37, 23-46.

Fabra, N., Toro, J., 2006b. Price Wars and Collusion in the Spanish Electricity Market" International Journal of Industrial Organization 23, 155-181.

Ferreira, J.L, Kujal, P., Rasenti S., 2009. The Strategic Motive to Sell Forward: Experimental Evidence, WP 09-26, Economic Series (16), Universidad Carlos III de Madrid.

Green, R., 1996. Increasing competition in the British Electricity Spot Market, The Journal of Industrial Economics 44(2), 205-216.

Kiesling, L., and Wilson, B.J., 2007. An experiment analysis of the effects of automated mitigation procedures on investment and prices in wholesale electricity markets, Journal of Regulatory Economics 31, 313-334. 
Haas, R., Auer, H., 2006. The prerequisites for effective competition in restructured wholesale electricity markets, Energy 31, 857-864.

Kuhn, K-U, Machado, M., 2001. Bilateral Market Power and Vertical Integration in the Spanish Electricity Spot Market, CEPR Discussion Paper No. 4590.

Kwoka, J.E., 2002. Vertical Economies in Electric Power: Evidence on Integration and its alternatives, International Journal of Industrial Organization 20, 653-671.

Loertscher, S., Reisinger, M., 2011. Market Structure and the Competitive Effects of Vertical Integration. University of Melbourne, Working paper series, $n^{0}$ 1136. ISSN: 0819-2642.

http://fbe.unimelb.edu.au/ data/assets/pdf file/0006/784293/1136.pdf

Mansur, E., 2007. Upstream Competition and Vertical Integration in Electricity Markets, Journal of Law and Economics 50, 125-156.

Marin, P.L., Garcia-Diaz, A., 2003. Strategic Bidding in Electricity Pools with Short-Lived Bids: An Application to the Spanish Market, International Journal of Industrial Organization 21(2), 201-222.

Newbery, D. 1999. Privatization, Restructuring, and Regulation of Network Utilities. MIT Press, Massachusetts.

Nillesen, P.H., Pollitt, M.G., 2011. Ownership Unbundling in Electricity Distribution: Empirical Evidence from New Zealand, Review of Industrial Organization 38, 61-93.

Rassenti, S. Smith, V., 2008. Deregulating electric power: market design issues and experiments, In: Plott, Charles R., Smith, Vernon L., (Eds.), Handbook of Experimental Economics Results, Volume 1, Elsevier, New York.

Rassenti, S.J., Smith, V.L., Wilson, B.J., 2003. Controlling market power and price spikes in electricity networks: Demand-side bidding, Proceedings of the National Academy of Sciences 100, 2998-3003.

Shawhan, D., Messer, K.D., Schulze, W.D., Schuler, R., 2011. An experimental test of automatic mitigation of wholesale electricity prices, International Journal of Industrial Organization 29, 46-53.

Sioshansi, F.P. 2008. Competitive electricity markets. Design, Implementation, Performance, Oxford: Elsevier.

Smirnov, N., 1939. On the Estimation of the Discrepancy Between Empirical Curves of Distribution for Two Independent Samples, Bulletin Mathematique de I'Universite de Moscou, 2, 3-14.

Staropoli, C., Jullien, C., 2006. Using laboratory experiments to design efficient market institutions: The case of wholesale electricity markets, Annals of Public Cooperative Economics 77(4), 555-577. Stoft, S. 2000. Power Market Economics: Designing Markets for Electricity. Wiley \& Sons.

Williamson, O., 1971. The Vertical Integration of Production: Market Failure Considerations, American Economic Review 61, 112-23. 